\title{
Smartphone and Musculoskeletal Risk Factors: A Systematic
}

\section{Review}

\section{Vahedi Z, Hajizadeh L and Garosi E*}

Department of Occupational Health Engineering, School of Public Health, Tehran University of Medical Sciences, Iran

*Corresponding author: Ehsan Garosi, Department of Occupational Health Engineering, School of Public Health, Tehran University of Medical Sciences, Iran, Tel: +989122822013; Email: egarosi@alumnus.tums.ac.ir

\section{Review Article \\ Volume 3 Issue 1}

Received Date: January 24, 2019

Published Date: February 04, 2019

DOI: $10.23880 /$ eoij-16000193

\section{Abstract}

Background: Smartphones (SPs) are one of the newest technologies that influence users' daily lives. These technologies have both improved and exerted negative effects on our ways of living. With this issue in mind, we conducted a systematic review of studies on how SPs are used and its effects on muscle activity and joint motion in people's upper extremities.

Objective: This systematic review was aimed at surveying the effects of different tasks and typing styles by SP on SP user musculoskeletal disorders.

Method: Articles on the level of muscular activity and the kinematics of neck, upper extremities, and wrist during SP use were searched over Google Scholar, PubMed, Research Gate, and Science Direct. The search yielded 513 articles, out of which 18 were selected on the basis of inclusion and eligibility criteria.

Result: The reviewed articles showed that muscle activity and joint movement in the neck, wrist, and fingers were highly associated with the manner by which SP features were used. Two-handed and one-handed grips required different degrees of extension in the wrist and thumb.

Conclusion: Although the reviewed studies provided various recommendations for the healthy and appropriate use of SPs, there continues to be a lack of research that establishes precise guidelines on working correctly with these devices. Such guidelines are important considering that the functions and applications of SPs are being rapidly developed.

Keywords: Smartphone; Musculoskeletal Disorders; Electromyography; Motion Capture/Analyzer

Abbreviations: SP: Smartphone; APL: Abductor Pollicis Longus; APB: Abductor Pollicis Brevis; ED: Extensor Digitorum (ED); VAS: Visual Analog Scale.

\section{Introduction}

According to the United Nations, the International Telecommunication Union reported that about four 


\section{Ergonomics International Journal}

billion cell phones were produced worldwide in 2008 and it is predicted to pass 2.87 billion user by 2020 [1]. Adults, adolescents, and children have at least one smartphone (SP) or another kind of handheld device. The popularity of SPs can be attributed to their low price, light weight, and ease of use. These devices have afforded people multiple applications, on-demand access to the Internet, and convenient texting, emailing, and calling, thus motivating users, especially teenagers and young adults, to spend considerable time on their devices. A study indicated that the frequency of daily SP use has increased, with Americans spending at least 2 hours per day and 20 hours per week on their phones [2].

The use of SPs is going to have a specific posture that involves neck muscles and thumb. In this position, users usually bend their neck and thumb near to its range of motion, most of the times [3]. Working with mobile phones does not require much physical power, but holding and using the devices require a basic load and force, especially when users carry out repetitive and highspeed tasks [4]. It is revealed that, Mobile phone users hold their devices below eye level while texting, a task that requires neck flexion.

Prolonged neck flexion while using SPs increases the risk of neck pain as it injures the vertebral bodies of the neck $[2,5,6]$. Gustaffson, et al. [7] in a cohort study on 7,092 SP users showed that after one year, the participants with no history of musculoskeletal disorders experienced pain in their hands and fingers, and the participants with a history of pain exhibited susceptibility to chronic neck and upper back disorders. Additionally, the findings also indicated that the continuous use of mobile phones in an awkward posture lead to long-term effects on the neck and upper extremities of the participants. Similarly, electromyography studies of healthy users conducted by Xie, et al. [8] and Shieh [9] showed that the participants felt pain in the neck and shoulders while texting.

In electromyography studies it was determined that during working by smartphones involve muscle activity of the abductor pollicis longus (APL), abductor pollicis brevis (APB), extensor digitorum (ED), and left and right trapezius are increased. Moreover, the speed of finger movements during abduction/adduction is higher than the speed of movement during flexion/extension [10].

Keypads and typing styles are other factors that need to be examined in relation to the above mentioned effects of SP use. Kietrys, et al. [11] showed that no association exists between keypads and typing styles but also indicated that these factors affect finger muscles instead of the trapezius [11]. According to the author, typing style influences neck flexion, whereas keypad type does not. The author also found that engaging with large touchscreens involves considerable neck flexion and high muscle activity in finger flexors, wrist extensors, and the trapezius. A study focusing on posture, typing style, and gender revealed that $91 \%$ of users exhibited a flexed neck posture and that $90.3 \%$ of users use their wrists in an unnatural position. A high proportion of the men exhibited shoulder protraction, and a high proportion of the women positioned their elbows at an angle less than 90 degrees, especially while standing. Over $46.1 \%$ of the subjects typed with both thumbs, and one-third typed with only the right thumb. No difference was observed between typing style and gender [12].

The studies discussed above can serve as a guide for professionals and practitioners in defining the problems related to SP use and establishing the best approaches to preventing such problems as these studies demonstrate the potential damage mechanisms that underlie texting [13]. The aim of the current research was to systematically evaluate previous studies on the manner by which SPs are used and such musculoskeletal risk factors that explored by objective methods. The results are expected to illuminate SP-related issues that have not been considered by scientists in the fields of technology and health care.

\section{Methodology}

Articles on the level of muscle activity and the kinematics of upper extremities during SP use were searched over Google Scholar, PubMed, Research Gate, and Science Direct (2007-2017) on July 2017. Figure 1 graphically illustrates the search strategy implemented in this work. The search was conducted using a combination or string of suggested keywords by experts in biomechanics and ergonomics keywords as follows: "(musculoskeletal disorders OR pain OR discomfort OR disorder) AND (upper extremities OR neck OR hand OR wrist) AND (electromyography OR motion capture/analyzer OR electrogoniometer) AND (smartphone OR mobile phone OR cellphone OR handheld device)."

The inclusion criteria were studies involving SP users and not tablet, notebook, or laptop (etc.) users; articles published in English; case studies, cross-sectional research, and cohort studies; and studies involving the use of electromyography, electrogoniometers, and motion capture. Literature reviews and pre-post interventional 


\section{Ergonomics International Journal}

studies were also excluded from the review. The database search yielded 513 articles, out of which 185 were excluded because of duplication and repetition. Initial 513 articles, out of which 185 were excluded because of duplication and repetition. After the remaining articles were read, a further 287 were eliminated because these studies used only the questionnaire method, disregarded the use of SPs in their examinations, involved psychosocial investigations and mental patients, or conducted only literature reviews. This left us with a final sample of 18 articles.

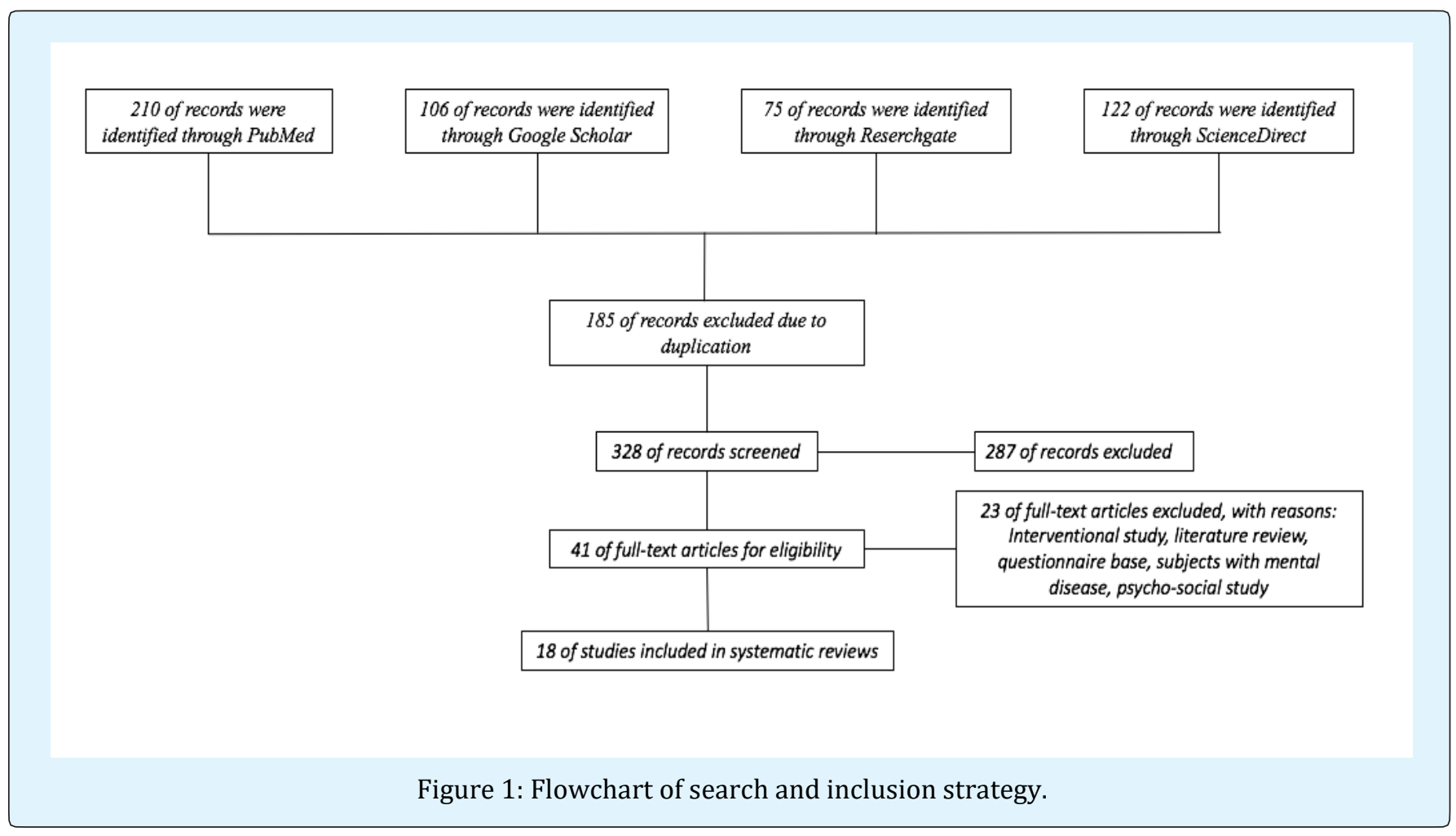

Reading and evaluating previous studies on the issue of interest require the supervision of professionals in biomechanics, anatomy, and ergonomics (posture) and familiarity with electromyography, motion capture, and electrogoniometers. We therefore asked a biomechanics expert and an ergonomics specialist to assist us in reading and selecting the full text of 41 selected articles.

\section{Results}

The results of the reviewed studies were organized under the following categories: general characteristics, SP features, environmental characteristics, postural issues of SP users, muscle activity and fatigue, and duration and questionnaire.

\section{General Characteristics}

General information and other details on the reviewed articles are presented in this section. We observed a decline in investigations in 2017 possibly because an interpretation for this year was too early at this point.

The participants in the reviewed studies were primarily females (136 females and 116 males) and were in their 20s [2,5,8,11,14-22]. Some of the study participants were more than 30 years old [11-15]; one study did not specify the age of the subjects. Eight articles indicated that the participants are right handed $[2,16,18,20,21,23-27]$. In terms of phone characteristics, two studies used emulated phones with physical keypads $[18,25]$, most of the studies involved SPs with touchscreens $\quad[2,5,8,15,16,19-21,23,24,26,27]$, two examined mobile phones with physical keypads $[14,22]$, and one examined two kinds of mobile phones with physical keypads and touchscreens [11]. In each study, the participants executed different tasks, among which the most frequently assigned were typing and sending messages $[14,22]$. Two studies allowed the participants to work on their phones in accordance with their own 


\section{Ergonomics International Journal}

preferences [19,24], three assigned reciprocal tapping tasks $[18,21,25]$, two involved tapping on emulated keys $[21,25]$, and one presented gaming tasks to the participants [15]. In some of the studies, the participants were asked to type 300 characters or only one or two sentences $[16,17,22]$. Task duration varied from 5 seconds [5,25] to 90 minutes [21]. One study evaluated various postures in three phases to determine the effects of posture on neck flexion [5].

\section{SP Properties}

According to the selected studies, typing on a physical keypad or touchscreen exerted different effects on neck flexion and wrist extension. Comparisons of physical keypads and touchscreens indicated that the former induced higher muscle activity in the abductor pollicies brevis (APB), flexor digitorum superficialis (FDS), and extensor carpi radialis (ECR) brevis and longus. Tapping on physical keypads also drove less neck flexion than did tapping on touchscreens, but a higher wrist extension angle was observed when tapping on touchscreens than on physical keypads. Additionally, a significant relationship was found between touchscreen size and muscle activity in the upper trapezius (UT) [11].

With increasing touchscreen size, the users preferred to lay their phones on their laps, thus motivating the researchers to conclude that SPs with large touchscreens (9 inches) trigger more flexion in the neck region. In comparison to two size of touchscreens, 9.5 inches caused a threefold increase in muscle activity in the APB, FDS, and ECR (11). Button size influenced performance, muscle activity, and tapping speed. On small buttons $(\mathrm{d}=3$ millimeters), tapping speed was slower, muscle activity in the first dorsal interossei (FDI) was higher, and the thumb became tired faster $(20,23)$ than on large buttons $(d=9$ millimeters) [23]. Different curvature rates had various effects on muscle activity. Kwon, et al. stated that an SP with a curvature radius of 100 (more curved on the backside) induced higher muscle activity in the APL and FDI than did SPs that are flat and have curvature radii of 300 and 200.

The author indicated that an SP with a curvature radius of 200 caused lower muscle activity in the two aforementioned muscles. A high body depth (11 millimeters) was more significantly associated with muscle activity in the APB, FDI, APL, and Extensor Digitorum (ED) than a low depth $(3,5$, and 7 millimeters) [16].
Different curvature rates had various effects on muscle activity. Kwon et al. stated that an SP with a curvature radius of 100 (more curved on the backside) induced higher muscle activity in the APL and FDI than did SPs that are flat and have curvature radii of 300 and 200. The author indicated that an SP with a curvature radius of 200 caused lower muscle activity in the two aforementioned muscles. Finally, the study found that a high body depth (11 millimeters) was more significantly associated with muscle activity in the APB, FDI, APL, and Extensor Digitorum (ED) than a low depth $(3,5$, and 7 millimeters) [16].

\section{Environmental Characteristics}

As stated in some of the studies, neck flexion was related to the placement of SPs by the users $[5,11]$. One study showed that working with SPs at table height increased muscle activity in the neck extensors to a level higher than that observed when SPs are placed on the lap [5]. The visual analog scale (VAS) indicated that SP positioning on the lap was scored higher by the participants than positioning at table height. The participants who used forearm support exhibited lower muscle activity in the right trapezius muscle while texting than did the participants who did not use such support. Forearm support during a single-handed grip decreased muscle activity in the left and right trapezius. Another study demonstrated that the neck pain felt by users with musculoskeletal disorders was associated with the nonuse of forearm and back support during SP use [22].

\section{Postural Issues of Smartphone Users}

Users grip their phones in different ways; they hold their devices with two hands or one hand or grip their phones while sitting or standing [2,18,27]. A two-handed grip induced extension in the joints of the wrists and thumbs (extension during a one-hand grip was 50\% lower), and the carpometacarpal joint of the thumb was remarkably more extended (5\%), abducted (3\%), and supinated $(8 \%)$ in a two-handed grip than in a onehanded grip. Also, Phone movement variations in all the three axes in a two-handed grip was 36\% to $63 \%$ lower than those in a single-handed grip, thus enabling greater phone stability in the former.

The index of performance was $9 \%$ greater, the time of movement was $7 \%$ faster, and taps were $4 \%$ more accurate in a two-handed grip. Another study indicated that a two-handed grip induced a greater level of motor activity [18]. Conversely, a single, right-handed grip caused more errors and induced lower performance in maneuvering the right side of a keypad. A relationship 


\section{Ergonomics International Journal}

was found between key positions in the right corner of a keypad and poor transition time and considerable errors in key taps $[16,25,27]$. A one-handed grip also resulted in greater pain in the UT and higher activity in the UT, extensor pollicis longus (EPL), and abductor pollicis (AP) muscles; interestingly, tapping on more keys from the base of the thumb (tapping on the left corner of a touchscreen while holding an SP with the right hand) induced higher activity in the APL and APB [16,25,27].

Given that a one-handed grip induced higher activity in the UT, EPL, and AP [27], a two-handed grip and typing with both thumbs on a physical keypad induced more neck flexion than did working with one hand and typing on a touchscreen [11]. The results of the reviewed studies showed that neck flexion was higher in tasks carried out while sitting than in tasks conducted while standing [2].

\section{Muscle Activity and Fatigue}

As indicated in the studies, different levels of muscle activity were observed during various mobile phone tasks. With increasing fatigue in the left and right splenius capitis and left UT, more neck flexion was exerted by the users [24]. The results on muscle activity and muscle fatigue varied, but no significant differences in muscle activity were found between the left and right splenius capitis and the left UT; however, significant differences in muscle fatigue were found between these muscles [17]. One of the studies revealed that 15 minutes of gaming caused different effects on the cervical erector spinae (CES), UT, lower trapezius (LT), and thoracic erector spinae (TES); an increase in gaming time reduced electromyographic activity and decreased the amplitudeprobability distribution function in the bilateral TES and LT by $10 \%$ but elevated activity in the bilateral erector spinae [15]. SP dimensions were recognized as an important factor that affects thumb posture and muscle activity.

Muscle activity in the ED and FDI were highly related to thumb posture and movement; these two muscles are not individually responsible for thumb movement but play a basic role in hand stability and rest [14]. The ED muscle showed a high level of activity as the users tapped at high speed through abduction-adduction movements, and the FDI muscle was activated in natural postures or low flexion in the thumb; this muscle was in a rest status as the thumb was involved in high flexion movements [14].

Thumb performance was at its best when it was neither significantly flexed nor completely extended (during medium activity in the FDI) [18]. Using the medial side or pad/tip of the thumb exerted different effects on muscle activity; key pressing with the medial side of the thumb triggered high forearm exertion and increased muscle activity in the FDI [22]. Key size also influenced the FDI, with small keys increasing perceived exertion and level of activity to a level higher than that observed with large keys [20,23]. Efforts to stabilize a phone while the thumb engages in high-velocity movement was associated with high activity in the ED muscle $[14,22]$.

\section{Task Duration}

Task duration generally affected muscle activity and fatigue. A study revealed that using SPs for 10 minutes reduced the mean frequency of fatigue in examined muscles, but none of the results were significant. The study also indicated that an increase in usage time from 20 to 30 minutes caused fatigue in the left UT, CES, and bilateral UT. Some of the studies found significant differences between VAS scores at the end of tasks and observed that the participants experienced pain at the end of 10, 30, and 16 minutes of usage [15,4]. According to Kim, et al. [24] pain at the end of $30 \mathrm{~min}$ was higher than 10 min of using SP [24].

The users with a history of musculoskeletal disorders had higher VAS scores than did the users without such disorders [22]. The following effects occurred with increasing task duration (specifically, gaming): neck flexion increased from 66.01 degrees at the beginning of gaming to 90.34 degrees after 15 minutes of gaming; after 15 minutes, trunk flexion decreased from almost 104.0 degrees initially to 81.65 degrees; and the angles at which upper cervical and lower cervical segments were positioned tended to increase $[15,19]$.

Selected studies also indicated that the nature of the tasks were another important factor and had various effects on muscles and joints. Based on these studies, text messaging and other typing tasks exerted stronger effects on neck flexion (about $45.6^{\circ}$ ) than did web browsing and video watching $[2,26]$; reading tasks induced less activity in neck extensor muscles than did typing and gaming [26]. 


\section{Ergonomics International Journal}

\begin{tabular}{|c|c|c|c|c|c|c|c|c|c|c|}
\hline \multirow{2}{*}{$\begin{array}{c}\text { No. } \\
\text { (Ref.No.) }\end{array}$} & \multirow[t]{2}{*}{ Authors } & \multirow[t]{2}{*}{$\begin{array}{c}\text { Year of } \\
\text { publication/journa }\end{array}$} & \multirow[t]{2}{*}{ Country } & \multirow{2}{*}{\begin{tabular}{|c|}
$\begin{array}{c}\text { Sample } \\
\text { size }\end{array}$ \\
Female \\
\end{tabular}} & \multirow{2}{*}{\multicolumn{2}{|c|}{\begin{tabular}{|c|c|} 
& $\begin{array}{c}\text { Target } \\
\text { limb }\end{array}$ \\
Male & Total \\
\end{tabular}}} & \multirow[t]{2}{*}{ Device } & \multirow{2}{*}{$\begin{array}{c}\text { Task } \\
\text { duration }\end{array}$} & \multirow{2}{*}{\multicolumn{2}{|c|}{ Mean age (SD) }} \\
\hline & & & & & & & & & & \\
\hline 1 [15] & Park, et al. & $\begin{array}{l}\text { 2017/Physiotherapy } \\
\text { Theory and Practice }\end{array}$ & $\begin{array}{l}\text { Republic } \\
\text { of Korea }\end{array}$ & - & - & 18 & CES, TES, UT, LT & \begin{tabular}{|c|} 
Electro \\
myography
\end{tabular} & $16 \min$ & $21.18( \pm 1.90)$ \\
\hline 2 [17] & Choi, et al. & $\begin{array}{c}\text { 2016/The Journal } \\
\text { of Physical Therapy } \\
\text { Science }\end{array}$ & $\begin{array}{l}\text { Republic } \\
\text { of Korea }\end{array}$ & - & - & 15 & $\begin{array}{c}\text { Splenius capitis, } \\
\text { UT }\end{array}$ & \begin{tabular}{|c|} 
Electro \\
myography
\end{tabular} & $\begin{array}{l}\text { Writing a } \\
\text { sentence }\end{array}$ & $20 \mathrm{~s}$ \\
\hline $3[8]$ & Xie, et al. & 2016/Ergonomics & China & 24 & 16 & 40 & $\begin{array}{l}\text { ECR, ED, FDS, } \\
\text { APB }\end{array}$ & \begin{tabular}{|c|} 
Electro \\
myography
\end{tabular} & 10 minutes & $23.9(+3.2)$ \\
\hline $4[23]$ & Xiong, et al. & 2016/SpringerPlus & Japan & 10 & 10 & 20 & $\begin{array}{c}\text { APB, APL, FDI, } \\
\text { ED }\end{array}$ & \begin{tabular}{|c|} 
Electro \\
myography
\end{tabular} & - & $65.5(+1.5)$ \\
\hline $5[24]$ & Kim, et al. & $\begin{array}{l}\text { 2016/Journal of } \\
\text { Physical Therapy } \\
\text { Science }\end{array}$ & $\begin{array}{l}\text { Republic } \\
\text { of Korea }\end{array}$ & & & 34 & CES and UT & $\begin{array}{c}\text { Electro } \\
\text { myography }\end{array}$ & $\begin{array}{c}10,20-30 \\
\text { minutes }\end{array}$ & 20 s and $30 s$ \\
\hline 6 [18] & Trudeau, et al. & $\begin{array}{l}\text { 2016/Applied } \\
\text { Ergonomics }\end{array}$ & USA & 5 & 5 & 10 & MCP, CMC, IP & $\begin{array}{c}\text { Active marker } \\
\text { motion } \\
\text { capture } \\
\text { system }\end{array}$ & $\begin{array}{c}\text { Tap } \\
\text { ouchscreen } \\
8 \text { times }\end{array}$ & $27( \pm 7.0)$ \\
\hline 7 [16] & Kwon, et al. & $\begin{array}{c}\text { 2016/Industrial } \\
\text { Ergonomics }\end{array}$ & $\begin{array}{l}\text { Republic } \\
\text { of Korea }\end{array}$ & 5 & 15 & 20 & $\begin{array}{c}\text { APB, APL, FDI, } \\
\text { ED }\end{array}$ & $\begin{array}{c}\text { Electro } \\
\text { myography }\end{array}$ & \begin{tabular}{|c|} 
Tapping, \\
dragging, \\
and writing \\
three \\
sentences \\
\end{tabular} & $25.8(+2.0)$ \\
\hline 8 [11] & Kietrys, et al. & $\begin{array}{c}\text { 2015/Applied } \\
\text { Ergonomics }\end{array}$ & USA & - & - & 20 & $\begin{array}{c}\text { UT, ECR, FDS, } \\
\text { APB }\end{array}$ & \begin{tabular}{|c|}
$\begin{array}{c}\text { Electro } \\
\text { myography }\end{array}$ \\
\end{tabular} & 10 seconds & $\begin{array}{c}\text { At least } 18 \\
\text { years old }\end{array}$ \\
\hline 9 [2] & Lee, et al. & 2015/Ergonomics & $\begin{array}{l}\text { Republic } \\
\text { of Korea }\end{array}$ & 9 & 9 & 18 & $\begin{array}{l}\text { Head flexion } \\
\text { angle }\end{array}$ & $\begin{array}{l}\text { Motion } \\
\text { capture } \\
\text { system }\end{array}$ & $\begin{array}{c}\text { Three tasks } \\
2 \text { minutes } \\
\text { each }\end{array} \mid$ & $20.2(+1.48)$ \\
\hline 10 [19] & Kim, et al. & $\begin{array}{l}\text { 2015/Journal of } \\
\text { Physical Therapy } \\
\text { Science }\end{array}$ & $\begin{array}{l}\text { Republic } \\
\text { of Korea }\end{array}$ & 15 & 12 & 27 & UC and LC & $\begin{array}{c}\text { Ultrasound- } \\
\text { based motion } \\
\text { analysis } \\
\text { system }\end{array}$ & 5 minutes & $20.6(+1.6)$ \\
\hline $11[26]$ & Ning, et al. & \begin{tabular}{|} 
2015/International \\
Journal of Industrial \\
Ergonomics
\end{tabular} & USA & 4 & 10 & 14 & CES & $\begin{array}{c}\text { Electro } \\
\text { myography }\end{array}$ & 1.5 minutes & - \\
\hline 12 [27] & Lee, et al. & $\begin{array}{l}\text { 2015/Journal of } \\
\text { Physical Therapy } \\
\text { Science }\end{array}$ & $\begin{array}{l}\text { Republic } \\
\text { of Korea }\end{array}$ & 10 & - & 10 & UT, EPL, AP & \begin{tabular}{|c|} 
Electro \\
myography
\end{tabular} & $\begin{array}{c}9 \text { minutes } \\
\text { of typing }\end{array}$ & $21( \pm 0.76)$ \\
\hline $13[5]$ & Shin, et al. & $\begin{array}{l}\text { 2014/Journal of } \\
\text { Physical Therapy } \\
\text { Science }\end{array}$ & $\begin{array}{l}\text { Republic } \\
\text { of Korea }\end{array}$ & - & & 15 & CES & \begin{tabular}{|c|} 
Electro \\
myography
\end{tabular} & 5 seconds & $26.07+(5.73)$ \\
\hline $14[20]$ & Xiong, et al. & 2014/Ergonomics & Japan & 10 & 10 & 20 & $\begin{array}{c}\text { FPB, APB, APL, } \\
\text { FDI, ED }\end{array}$ & \begin{tabular}{|c|} 
Electro \\
myography
\end{tabular} & - & $24.5(+2.2)$ \\
\hline $15[25]$ & Trudeau, et al. & \begin{tabular}{|c|}
$2012 /$ Human \\
Factors: The Journal \\
of the Human \\
Factors and \\
Ergonomics Society
\end{tabular} & & - & - & 20 & CMP joint & - & 5 seconds & $\begin{array}{l}\text { From } 18 \text { to } 35 \\
(\text { mean }=25)\end{array}$ \\
\hline $16[21]$ & Trudeau, et al. & $\begin{array}{c}\text { 2012/Journal of } \\
\text { Biomechanics }\end{array}$ & & 5 & 5 & 10 & CMC joint & $\begin{array}{l}\text { Motion } \\
\text { capture } \\
\text { system }\end{array}$ & 90 minutes & $27(+7.0)$ \\
\hline
\end{tabular}




\section{Ergonomics International Journal}

\begin{tabular}{|c|c|c|c|c|c|c|c|c|c|c|}
\hline 17 [2] & $\begin{array}{c}\text { Gustafsson, et } \\
\text { al. }\end{array}$ & 2011/Ergonomics & & 31 & 25 & 56 & $\begin{array}{c}\text { APB, APL, FDI, } \\
\text { ED, pars } \\
\text { descendents of } \\
\text { the right and left } \\
\text { trapezius }\end{array}$ & $\begin{array}{c}\text { Electro } \\
\text { myography }\end{array}$ & $\begin{array}{c}\text { Writing } 300 \\
\text { characters }\end{array}$ & $19-25$ \\
\hline $18[14]$ & Jonsson, et al. & $\begin{array}{c}\text { 2011/Journal of } \\
\text { Electromyography } \\
\text { and Kinesiology }\end{array}$ & & 7 & 8 & 15 & $\begin{array}{c}\text { APB, APL, FDI, } \\
\text { ED, }\end{array}$ & $\begin{array}{c}\text { Electro } \\
\text { myography }\end{array}$ & $\begin{array}{c}222 \\
\text { seconds } \\
\text { (average) }\end{array}$ & \\
\hline
\end{tabular}

Table 1: Items of interest in each study.

APB: abdutor pollicis brevis, $\mathbf{A P L}=$ abductor pollicis longus, FDI = first dorsal interossei, ED = extensor digitorum, ECR = extensor carpi radialis, FDS = flexor digitorum superficialis, $\mathbf{D I P}=$ distal interphalangeal, $\mathbf{P I P}=$ proximal interphalangeal, $\mathbf{M C P}=$ metacarpophalangeal, $\mathbf{I P}=$ the thumb interphalangeal, $\mathbf{M C P}=$ metacarpophalangeal, $\mathbf{C M C}=$ carpometacarpal, $\mathbf{C E S}$ = cervical erector spinae, $\mathbf{T E S}=$ thoracic erector spinae, $\mathbf{U T}=$ upper trapezius, $\mathbf{L T}=$ lower trapezius, $\mathbf{E P L}=$ extensor pollicis longus, $\mathbf{A P}=$ abductor pollicis, $\mathbf{U C}=$ upper cervical spinae, $\mathbf{L C}=$ lower cervical spinae

\section{Discussion}

The main goal of this paper was to reveal the existed study over SPs and reviewing its relationships between duration, feature of SP and MSDs. Most of the selected studies were laboratories studies that examined the effect of different tasks, SP features, condition of study like kind of SP grip, and different level of muscular activity. Selecting laboratories studies decreases chance of bias which is very common in questionnaire based studies. EMG and motion capture were two used devices in studies, also mistakes in detecting the belly of muscles and chance of cross-talk in EMG is not negligible.

The review revealed evidence that different tasks and typing styles are associated with neck flexion and musculoskeletal disorders among users of SPs. Repetitive and prolonged activity is known as the most impressive factor associated with any kind of handheld device. Users continue using their devices in the manner that they are accustomed to until they feel pain and discomfort in the neck, shoulders, hands, and fingers possibly and unfortunately no threshold for SP use has been suggested. Among the SP features examined in the reviewed literature, touchscreen size was a major factor that affected the users' musculoskeletal systems.

It is obvious that large screen size devices contain more materials, so resulted in a heavier SP; thus, size and weight are significantly related to increased neck flexion. A previous study on older technologies identified notebook and computer size as a factor in musculoskeletal disorders among users; such factor was also considered by Szelto and Lee, who found that a reduction in display size induced higher cervical and thoracic flexion [28]. Additionally, muscle activity was highly associated with SP features, SP tasks, and postures.
Increased activity in the trapezius muscle was observed due to the growing size of touchscreens, not using of forearm support, task duration, and use of a one-handed grip $[8,11,15,22,27]$. The vicious circle model that muscle pain likely leads to enhanced muscle activity during muscle work, lead the muscles to increase their activity.

On this basis, one study revealed that high electromyography activity occurred in the neck and shoulder muscles of subjects with neck and shoulder complaints [10]. The association among keyboard type, neck flexion, and muscle activity suggested that physical keypads more strongly influence suggested that physical keypads more strongly influence activity in hand muscles and stimulate lower wrist flexion (angle) than do touchscreens [11]. Low performance, high FDI activity, slow tapping, and tiredness in the thumbs can also be attributed to the use of small buttons ( $\mathrm{d}=3$ millimeters) $[20,23]$. By investigating about the effect of different tasks, among all popular tasks in smartphone users, texting and typing were the strongest factor for neck flexion $[2,26]$.

The design of SPs was informed by evidence regarding the risk factors associated with older technologies; now, the nature of SP use is that tasks are repetitive and require lengthy periods of holding a device [29,30]. Repetitiveness and prolonged gripping while texting cause hand pain-a phenomenon so prevalent among BlackBerry users that that condition was accorded its own term, that is, "BlackBerry thumb" (or hand) [29,30]. Finger and wrist positions influence deformity in the median nerve, which causes numbness and clumsiness in hand movements involved in daily routines [12,31-33]. The SP-related neck pain known as text neck syndrome is a result of maintained and awkward posture while texting, especially when a user is holding a heavy SP for a long period as his/her neck is flexed [2,34]. 


\section{Ergonomics International Journal}

Maintained and static posture and prolonged duration of using SP show the occurrence of pain and discomfort, visual analog scale (VAS) is a simple way to evaluate effort in participants. The VAS reports of the participants in the reviewed studies indicated that increased SP usage elevated pain levels [24]; and that neck pain was greater than trunk pain when SPs were positioned on the lap than at desk level, which means working on SP at a level closer to the eye-height level provides lower neck flexion in users $[5,15]$.

A history of musculoskeletal disorders was also associated with discomfort scores; symptomatic subjects presented more severe pain in the neck and shoulder than asymptomatic participants, especially when the participants used a single-handed grip [8]. A one-year follow up with the symptomatic and asymptomatic subjects showed an increase in neck and shoulder pain; however, the pain vanished after a five-year follow up in both groups possibly because of changes to phone model, texting style, and phone grip [7]. Pain among users of SPs is not studies on older technologies presented the same results, indicating that computer and notebook users are at risk of acute pain in the neck and shoulder $[35,36]$.

Generally, posture influenced an SP user's joint motions. Sitting or standing and a one-handed or twohanded grip exerted various effects on neck and wrist deviations. Varying degrees of neck flexion were observed during different tasks, such as typing, video watching, and web browsing, but sitting generally induced higher neck flexion than did standing in all tasks, particularly during texting [2]. A two-handed grip induced higher wrist extension, abduction, and supination, but it also enabled a higher index of performance, faster movement, and greater stability [18].

Muscle activity was highly associated with SP features, SP tasks, and postures. Increased activity in the trapezius muscle was due to the growing size of touchscreens, not using of forearm support, task duration, and the use of a one-handed grip $[8,11,15,22,37]$.

Stability and the rest were observed in the FDI and ED muscles during SP use. Pressing small buttons while using the medial side of the thumb directly influenced in increasing activity in the FDI. Activity in the ED muscle was highly related to efforts to stabilize an SP as the thumb moved at high speeds $[14,20,22,23]$. On this basis, then, SP stabilization and speedy typing increased electromyographic activity in the ED muscle.
Interestingly, SP users are tend to keep their neck forward flexion posture even by increasing and existence of pain and discomfort on upper extremities and neck [2].

Most of the time, therefore, they may assume unnatural postures-an issue that may have been neglected by the majority of the literature. Usually, having unnatural neck posture occurs with increased flexion in the neck; many of the reviewed studies investigated neck flexion in relation to SP use, but only one examined the condition while users are sitting and standing [2].

Trudeau, et al. [38] and Kietrys, et al. [11] amined the issue during the performance of different tasks and under varying typing styles in separate studies, but this matter requires more accurate investigations with greater intervals than that adopted in conventional studies to ensure that muscle activity is close to daily activity and accurately determine the influence of muscle fatigue on neck flexion.

After evaluating the studies, we realized that none of them devoted attention to the influence of phone cases and accessories on gripping and neck flexion (Increased phone thickness may affect muscle activity). Limitations on selected articles are important to be clarified. Authors of selected studies were faced with some limitations like: natural position was defined 0 degrees in the neck region, but this degree is never possible in real life. Also, not only neck flexion needed to be measured, but also the effect of head rotation and lumbar flexion needed to be investigated in future studies $[2,19]$.

Studies mostly were invited participants in their 20s and results cannot be generalized for sample groups with different ages and various characteristics. [16,17,21,25]. Participants were asked to work with SPs for a short time, which is done typically longer in daily usage $[2,5,24]$. Needing follow-up studies in different occasion like in transportation systems (subway or bus) and even walking [17].

Some of the selected studies claimed that small sample size was a remarkable limitation $[15,17,18]$. Another important factor was considering different functions like net browsing, gaming, reading, and video watching $[2,8]$. Additionally, Differences in using Android, IOS, and Windows needed to be investigated too $[8,26]$. Working with SP with non-dominant hand was not considered. Also, selecting data in landscape and portrait mode should be considered [18]. Furthermore, selected studies claimed that all features of SP like length, depth, back and 


\section{Ergonomics International Journal}

front curvature, and weight needed to be under more investigations $[16,25,26]$.

Having ample time before each investigation or prior experiences with devices in the study should be considered in further studies [11] Using self-reported questionnaires were considered as a limitation in order to increase chance of bias in the answers [39]. In postural issue, comparing posture of users with natural and normal postures with choosing postures by participants was not considered [24]. Another missed factor was having no approach in detecting threshold of injuries and muscular fatigue [23]. In selecting muscle for EMG tests, there was no possibility of choosing all muscles, so for example, among 8 muscles just 2 of them had been investigated [14,22].

\section{Limitation}

The limitations in selecting articles are worth discussing. First, we excluded investigations based on the questionnaire method (which is a very popular approach in SP studies). We endeavored to prevent biases triggered by personal comments; for example, with respect to the daily use of mobile phones, the participants may have provided durations lower or greater than actual usage times; with regard to the self-expression of pain, they may have indicated less or more pain than the actual level experienced and thereby increased the probability of errors and biases in the obtained results. Second, all the risk factors discussed in the review were physical in scope, but the cognitive and general conditions of adult SP users (e.g., being elderly or impaired) were not negligible. In the initial sample, some studies focused on the usability of touchscreens, the performance of elderly SP users, the behavioral differences in using electronic devices, and deaf or blind users, but we excluded these studies from the review to evaluate the effect of SP on healthy and normal users [40-47].

\section{Conclusion}

This systematic review identified SP features, environmental conditions, typing styles, grip styles (oneand two-handed), and task durations as some of the known risk factors that affect SP users' musculoskeletal systems. In thumb, neck, wrist and shoulders. The duration of tasks in selected studies was in the range of 5 Sec. To $90 \mathrm{~min}$. but studies revealed that users of SPs Usually spend from 2-5 hours per day on their SPs $[2,11,18]$. Interestingly, this small amount of time had shown a significant pain and discomfort in users and even 15 min gaming creates pain in neck and shoulders [15].
Spending long periods of time on a repetitive task and using certain muscles lead to pain and injuries in muscular fibers [24] so, it can infer that this symptom of MSDs is related to the time of SP usage. Regarding to Kim, et al. [24] task duration and repetitive tasks have influence on muscle fatigue, in prolonged activity more muscles involved in activity and finally fatigue occurs. It is clear that more studies are needed on Smartphones use with longer task duration than current studies and also further study will be beneficial in illuminating the current gap between tasks duration and muscle activity. It is revealed, no time limit is scientifically reported as a standard time for using SP. However, it's logical to advise users to limit and alternate time, but users tend to continue using of SP even when they feel pain and discomfort in the neck [48].

There is a need of more investigations about the characteristics of the SP and its effects on the occurrence of musculoskeletal disorders. Lack of guidelines in designing of SP can be a factor in releasing SP by companies in various shapes and features; also it is an important factor that needs to be considered in future studies.

\section{References}

1. Section UNNS. United Nations News Centre United Nations-DPI/NMD - UN News Service Section.

2. Lee S, Kang H, Shin G (2015) Head flexion angle while using a smartphone. Ergonomics 58(2): 220-226.

3. Berolo S, Wells RP, Amick BC (2011) Musculoskeletal symptoms among mobile hand-held device users and their relationship to device use: A preliminary study in a Canadian university population. Appl Ergon 42(2): 371-378.

4. Shan Z, Deng G, Li J, Li Y, Zhang Y, et al. (2013) Correlational Analysis of neck/shoulder Pain and Low Back Pain with the Use of Digital Products, Physical Activity and Psychological Status among Adolescents in Shanghai. PLoS One 8(10): e78109.

5. Shin H, Kim K (2014) Effects of Cervical Flexion on the Flexion-relaxation Ratio during Smartphone Use. J Phys Ther Sci 26(12): 1899-1901.

6. Jung SI, Lee NK, Kang KW, Kim K, Lee DY (2016) The effect of smartphone usage time on posture and respiratory function. J Phys Ther Sci 28(1): 186-189. 
7. Gustafsson E, Thomée S, Grimby-Ekman A, Hagberg M (2017) Texting on mobile phones and musculoskeletal disorders in young adults: A fiveyear cohort study. Appl Ergon 58: 208-214.

8. Xie Y, Szeto GPY, Dai J, Madeleine P (2015) A comparison of muscle activity in using touchscreen smartphone among young people with and without chronic neck-shoulder pain. Ergonomics 59(1): 6172.

9. Shieh KK, Lee DS (2007) Preferred viewing distance and screen angle of electronic paper displays. Appl Ergon 38(5): 601-608.

10. Gustafsson E, Johnson PW, Hagberg M (2010) Thumb postures and physical loads during mobile phone useA comparison of young adults with and without musculoskeletal symptoms. J Electromyogr Kinesiol 20(1): 127-135.

11. Kietrys DM, Gerg MJ, Dropkin J, Gold JE (2015) Mobile input device type, texting style and screen size influence upper extremity and trapezius muscle activity, and cervical posture while texting. Appl Ergon 50: 98-104.

12. Gold JE, Driban JB, Thomas N, Chakravarty T, Channell $V$, et al. (2012) Postures, typing strategies, and gender differences in mobile device usage: An observational study. Appl Ergon 43(2): 408-412.

13. Dennerlein JT (2015) The state of ergonomics for mobile computing technology. Work 52(2): 269-277.

14. Jonsson P, Johnson PW, Hagberg M, Forsman M (2011) Thumb joint movement and muscular activity during mobile phone texting - A methodological study. J Electromyogr Kinesiol 21(2): 363-370.

15. Park JH, Kang SY, Lee SG, Jeon HS (2017) The effects of smart phone gaming duration on muscle activation and spinal posture: Pilot study. Physiother Theory Pract 33(8): 661-669.

16. Kwon S, Bahn S, Ahn SH, Lee Y, Yun MH (2016) A study on the relationships among hand muscles and form factors of large-screen curved mobile devices. Int J Ind Ergon 56: 17-24.

17. Choi JH, Jung MH, Yoo KT (2016) An analysis of the activity and muscle fatigue of the muscles around the neck under the three most frequent postures while using a smartphone. J Phys Ther Sci 28(5): 16601664.

18. Trudeau MB, Asakawa DS, Jindrich DL, Dennerlein JT (2016) Two-handed grip on a mobile phone affords greater thumb motor performance, decreased variability, and a more extended thumb posture than a one-handed grip. Appl Ergon 52: 24-28.

19. Kim MS (2015) Influence of neck pain on cervical movement in the sagittal plane during smartphone use. J Phys Ther Sci 27(1): 15-17.

20. Xiong J, Muraki S (2014) An ergonomics study of thumb movements on smartphone touch screen. Ergonomics 57(6): 943-955.

21. Trudeau MB, Young JG, Jindrich DL, Dennerlein JT (2012) Thumb motor performance varies with thumb and wrist posture during single-handed mobile phone use. J Biomech 45(14): 2349-2354.

22. Gustafsson E, Johnson PW, Lindegård A, Hagberg M (2011) Technique, muscle activity and kinematic differences in young adults texting on mobile phones. Ergonomics 54(5): 477-487.

23. Xiong J, Muraki S (2016) Thumb performance of elderly users on smartphone touchscreen. Springerplus 5(1): 4-9.

24. Kim SY, Koo SJ (2016) Effect of duration of smartphone use on muscle fatigue and pain caused by forward head posture in adults. J Phys Ther Sci 28(6): 1669-1672.

25. Trudeau MB, Udtamadilok T, Karlson AK, Dennerlein JT (2012) Thumb Motor Performance Varies by Movement Orientation, Direction, and Device Size During Single-Handed Mobile Phone Use. Hum Factors Ergon Soc 54(1): 52-59.

26. Ning X, Huang Y, Hu B, Nimbarte AD (2015) Neck kinematics and muscle activity during mobile device operations. Int J Ind Ergon 48: 10-15.

27. Lee M, Hong YYY, Lee S, Won J, Yang J, et al. (2015) The effects of smartphone use on upper extremity muscle activity and pain threshold. J Phys Ther Sci 27(6): 1743-1745.

28. Szeto GP, Lee R (2002) An ergonomic evaluation comparing desktop, notebook, and subnotebook computers. Arch Phys Med Rehabil 83(4): 527-532. 


\section{Ergonomics International Journal}

29. O'Sullivan B (2013) Beyond BlackBerry thumb. CMAJ 185(4): 185-186.

30. Sharan D, Mohandoss M, Ranganathan R, Jose J (2014) Musculoskeletal disorders of the upper extremities due to extensive usage of hand held devices. Ann Occup Environ Med 26: 22.

31. Ko P, Hwang Y, Liang H (2015) Influence of smartphone use styles on typing performance and biomechanical exposure. Ergonomics 59(6): 821-828.

32. Åkesson I, Hansson GÅ, Balogh I, Moritz U, Skerfving S (1997) Quantifying work load in neck, shoulders and wrists in female dentists. Int Arch Occup Environ Health 69(6): 461-474.

33. Grandy EL, Xiu K, Marquardt TL, Li C, Evans PJ, et al. (2017) Carpal tunnel syndrome impairs index finger responses to unpredictable perturbations. J Electromyogr Kinesiol 38: 197-202.

34. Cuéllar JM, Lanman TH (2017) "Text neck": an epidemic of the modern era of cell phones? Spine J 17(6): 901-902.

35. Eltayeb S, Staal JB, Hassan A, De Bie RA (2009) Work related risk factors for neck, shoulder and arms complaints: A cohort study among Dutch computer office workers. J Occup Rehabil 19(4): 315-322.

36. Andersen JH, Harhoff M, Grimstrup S, Vilstrup I, Lassen CF, et al. (2008) Computer mouse use predicts acute pain but not prolonged or chronic pain in the neck and shoulder. Occup Environ Med 65(2): 126131.

37. Lee M, Hong YY, Lee S, Won J, Yang J, et al. (2015) The effects of smartphone use on upper extremity muscle activity and pain threshold. J Phys Ther Sci 27(6): 1743-1745.

38. Young JG, Trudeau M, Odell D, Marinelli K, Dennerlein JT (2012) Touch-screen tablet user configurations and case-supported tilt affect head and neck flexion angles. Work 41(1): 81-91.

39. Kim HJ, Kim JS (2015) The relationship between smartphone use and subjective musculoskeletal symptoms and university students. J Phys Ther Sci 27(3): 575-579.
40. Page T (2014) Touchscreen mobile devices and older adults: a usability study. Int J Hum Factors Ergon 3(1): 65.

41. Barnard Y, Bradley MD, Hodgson F, Lloyd AD (2013) Learning to use new technologies by older adults: Perceived difficulties, experimentation behaviour and usability. Computers Human Behavior 29(4): 17151724.

42. Hwangbo H, Yoon SH, Jin BS, Han YS, Ji YG (2013) A Study of Pointing Performance of Elderly Users on Smartphones. Int J Hum Computer Interact 29(9): 604-618.

43. Nicolau H, Jorge J (2012) Elderly text-entry performance on touchscreens. In: Proceedings of the 14th international ACM SIGACCESS conference on Computers and accessibility Boulder, Colorado, USA, pp: 127-134.

44. Kang NE, Yoon WC (2008) Age and experience related user behavior differences in the use of complicated electronic devices. Int J Hum Comput Stud 66(6): 425437.

45. Issenman RM, Jaffer IH (2004) Use of Voice Recognition Software in an Outpatient Pediatric Specialty Practice. Pediatrics 114(3): e290-e293.

46. Rodrigues A, Montague K, Nicolau H, Guerreiro T (2015) Getting Smartphones to Talkback: Understanding the Smartphone Adoption Process of Blind Users. In: Proceedings of the 17th International ACM SIGACCESS Conference on Computers \& Accessibility-ASSETS '15, ACM Press, New York, USA, pp: 23-32.

47. Chiti S, Leporini B (2012) Accessibility of AndroidBased Mobile Devices: A Prototype to Investigate Interaction with Blind Users. Springer, Berlin, Heidelberg 7383: 607-614.

48. Maniwa H, Kotani K, Suzuki S, Asao T (2013) Changes in Posture of the Upper Extremity Through the Use of Various Sizes of Tablets and Characters. In Springer, Berlin, Heidelberg 8016: 89-96. 